\title{
PENETAPAN KADAR ASAM BENZOAT PADA MARGARIN BERMERK KEMASAN DAN BERMERK CURAH DI WILAYAH PASAR CISALAK DEPOK
}

\author{
*Catu Umirestu Nurdiani ${ }^{1)}$, Marselina D Ismail ${ }^{1)}$ \\ ${ }^{1}$ Program Studi Analis Kesehatan, Fakultas Kesehatan, Universitas Mohammad Husni Thamrin \\ Correspondence author: Catu Umirestu Nurdiani, ctani_enan@yahoo.com, Jakarta, Indonesia
}

\begin{abstract}
ABSTRAK
Margarin merupakan salah satu produk berbasis lemak nabati yang luas penggunaannya dalam proses pengolahan makanan. Produk margarin menggunakan asam benzoat sebagai bahan pengawet organik untuk mencegah terjadinya kerusakan oleh aktivitas mikroba. Asam benzoat sebagai pengawet margarin dengan takaran yang rendah tidak menimbulkan efek atau gangguan pada tubuh manusia apabila penggunaannya berlebih akan menimbulkan toksisitas pada konsumen, maka dalam penggunaannya bahan tambahan makanan ini tidak boleh melebihi batas ketentuan yang berlaku yaitu $1000 \mathrm{mg} / \mathrm{kg}$.Tujuan penelitian ini adalah mengetahui kadar asam benzoat pada margarin bermerk dalam kemasan dan bermerk dalam curah di Wilayah Pasar Cisalak Depok. Pemeriksaan laboratorium asam benzoat pada margarin melalui uji kualitatif dengan $\mathrm{FeCl}_{3}$ dan uji kuantitatif dengan metode spektrofotometri untuk mengetahui kadar asam benzoat pada margarin. Sampel yang diambil sebanyak 10 sampel margarin yaitu 5 sampel margarin bermerk dalam kemasan dan 5 sampel margarin bermerk dalam curah.Dari 10 sampel margarin semua margarin menggunakan asam benzoat sebagai pengawet. Terdapat 2 sampel margarin dengan kadar melebihi batas standar Peraturan Kepala Badan Pengawas Obat dan Makanan yaitu pada margarin bermerk IDR dan bermerk MGR 1.
\end{abstract}

Kata Kunci : Margarin, Asam Benzoat, Pengawet Bahan Pangan

\section{ABSTRACT}

Margarine is one of the most widely used vegetable fat-based products in the food processing process. Margarine products use benzoic acid as an organic preservative to prevent damage from microbial activity. Benzoic acid as a preservative of margarine with a low measure does not cause any effect or disturbance on the human body if its overuse will cause toxicity in consumers, so in its use these food additional ingredients should not exceed the applicable provision limit of $1000 \mathrm{mg} / \mathrm{kg}$. The purpose of this research is to find out the levels of benzoic acid in margarine branded in packaging and branded in bulk in the Market Area of Cisalak Depok. Laboratory examination of benzoic acid in margarine through qualitative testing with $\mathrm{FeCl} 3$ and quantitative testing with spectrophotometric methods to determine benzoic acid levels in margarine. The samples were taken as many as 10 margarine samples, namely 5 branded margarine samples in packaging and 5 margarine samples branded in bulk. Of the 10 margarine samples all margarine uses benzoic acid as a preservative. There are 2 samples of margarine with levels exceeding the standard limit of the Regulation of the Head of the Food and Drug Control Agency namely on margarine branded IDR and branded MGR 1 .

Keywords : Margarine, Benzoic Acid, Food Preservatives

Open Journal System (OJS): journal.thamrin.ac.id 


\section{PENDAHULUAN}

Bahan pengawet makanan (BTM) adalah bahan yang ditambahkan pada makanan yang mampu menghambat dan menghentikan proses fermentasi, pengasaman atau bentuk kerusakan lainnya. Secara umum bahan tambahan makanan yang ditambahkan ke dalam makanan bertujuan untuk mengetahui komposisi dan penambahan bahan tersebut, misalnya untuk memperbaiki nilai gizi, mempertahankan kesegaran, cita rasa dan membantu pengolahan (Cahyadi,2012:6).

Beberapa bahan tambahan makanan sebagai pengawet ada yang membahayakan kesehatan, baik dengan reaksi langsung maupun tidak langsung. Reaksi langsung antara lain : muntah-muntah, diare, atau pusing. Sementara efek atas pengkonsumsian bahan pengawet yang bersifat tidak langsung atau menumpuk (akumulatif) dirasakan dalam jangka panjang sehingga membuat konsumen menjadi pihak yang dirugikan. Bahan tambahan makanan tersebut juga sangat potensial menimbulkan penyakit kanker (Yayasan Lembaga Konsumen Indonesia,2003).

Bahan pengawet yang boleh dicampurkan pada makanan adalah bahan tambahan yang telah mendapat izin beredar dari Departemen Kesehatan. Contohnya Natrium benzoat, Asam sorbat, Natrium bisulfit (terdaftar di Departemen Kesehatan RI, dengan simbol SP) (Dep.Pertanian,2002).

Beberapa produk olahan memerlukan bahan tambahan makanan (BTM) berupa pengawet untuk memperpanjang masa penyimpanannya. Salah satunya adalah margarin yang diolah. Produk-produk margarin menggunakan natrium benzoat sebagai bahan pengawet organik untuk mencegah terjadinya kerusakan oleh aktivitas mikroba. Batas maksimum penggunaan pengawet natrium benzoat di dalam margarin berdasarkan Peraturan Kepala Badan Pengawas Obat Dan Makanan RI Nomor 36 tahun 2013 adalah 1000 mg/kg.

Margarin merupakan salah satu produk berbasis lemak yang luas penggunaannya dalam proses pengolahan makanan. Margarin biasa digunakan sebagai olesan untuk langsung dimakan, maupun sebagai campuran adonan dalam proses baking maupun cooking untuk memberikan tekstur yang baik serta cita rasa pada makanan. Bahan utama dalam pembuatan margarin adalah lemak margarin. Margarin yang baik adalah margarin yang berbentuk padat dalam suhu ruang namun memiliki daya oles yang baik serta mampu meleleh dalam suhu tubuh, sehingga salah satu parameter penting yang diperhatikan dalam pembuatan margarin adalah sifat pelelehannya. Pembuatan margarin umumnya menggunakan campuran lemak dengan titik leleh tinggi dan titik leleh rendah yang diharapkan mampu memberikan lemak margarin dengan karakteristik Slip Melting Point (SMP) pada kisaran suhu tubuh yaitu $36-37^{\circ} \mathrm{C}$ serta karakteristik margarine yang lain seperti Solid Fat Index (SFI) yang sesuai persyaratan pembuatan margarin (Ketaren,1995).

Penggunaan bahan pengawet natrium benzoat tidak selalu aman terutama jika digunakan dalam jumlah berlebihan. Pengkonsumsian natrium benzoat secara berlebihan dapat menyebabkan keram perut, rasa kebas dimulut, bagi mereka yang mengalami lelah atau mempunyai penyakit ruam kulit (seperti jenis urtikaria dan eksema) pengawet ini dapat memperburuk keadaan, juga bersifat menumpuk (akumulatif) yang potensial menimbulkan penyakit kanker dalam jangka panjang dan ada juga laporan yang menunjukkan bahwa pengawet dapat merusak sistem saraf (Awang,2003).

Pada laporan penelitian sebelumnya oleh David Mulyantoro tahun 2015 didapatkan hasil kadar asam benzoat yang melebihi batas Peraturan Kepala Badan Pengawas Obat Dan Makanan pada margarin bermerk dalam kemasan yaitu dengan merk PMS dengan kadar 1201,06 mg/kg, dan margarin bermerk dalam curah yaitu dengan 
merk MC dengan kadar 1695,34 mg/kg, SMS dengan kadar 1046,92 mg/kg, dan PML dengan kadar 1301,07 $\mathrm{mg} / \mathrm{kg}$.

Berdasarkan latar belakang di atas maka diadakan penelitian terhadap berbagai margarin bermerk dalam kemasan dan bermerk dalam curah oleh Badan Pengawas Obat dan Makanan dengan ketentuan Peraturan Kepala Badan Pengawas Obat dan Makanan No. 36 tahun 2013 dengan batas maksimum $1000 \mathrm{mg} / \mathrm{kg}$ yang beredar di Wilayah Pasar Cisalak Depok dengan prinsip pemeriksaan menggunakan uji kualitatif dan uji kuantitatif.

\section{METODE PENELITIAN}

Penelitian ini dilakukan di Laboratorium Pangan Fakultas Kesehatan Universitas MH. Thamrin Jakarta Timur. Penelitian dilakukan pada tanggal 27-31 Juli 2018. Populasi pada penelitian ini adalah margarin yang bermerk dalam kemasan dan margarin bermerk dalam curah yang beredar di Wilayah Pasar Cisalak Depok. Sampel yang digunakan pada penelitian ini adalah margarin yang dijual di Pasar Cisalak Depok sebanyak 10 sampel yaitu 5 sampel yang bermerk dalam kemasan dan 5 sampel yang bermerk dalam curah.Dalam memperoleh data - data dilakukan sebagai berikut :Mensurvei pasar Cisalak Depok yang menjual margarin. Membeli sampel margarin. Dilakukan pemeriksaan di laboratorium pangan. Universitas MH. Thamrin Jakarta. Pemeriksaan menggunakan uji kualitatif menggunakan larutan $\mathrm{FeCl}_{3}$ dan uji kuantitatif dengan metode spektrofotometri.

\section{HASIL DAN PEMBAHASAN}

\section{Hasil}

Hasil dari pembacaan terhadap uji kualitatif dengan metode uji $\mathrm{FeCl}_{3}$ dan uji kuantitatif dengan metode spektrofotometri didapatkan hasil yaitu :

Tabel 3.

Hasil Pemeriksaan Asam Benzoat Secara Kualitatif Dan

Kuantitatif Pada Margarin Bermerk Dalam Kemasan Yang Dijual Di Pasar Cisalak Depok

\begin{tabular}{|c|c|c|c|c|}
\hline & $\begin{array}{c}\text { Sampel } \\
\text { NO }\end{array}$ & $\begin{array}{c}\text { Margarin } \\
\text { Bermerk } \\
\text { dalam } \\
\text { kemasan }\end{array}$ & Kemeriksaan Laboratorium & \multirow{2}{*}{$\begin{array}{c}\text { Memenuhi Syarat/ } \\
\text { Tidak Memenuhi syarat }\end{array}$} \\
\hline 1 & PLA & Terjadi Endapan Coklat $(+)$ & 100,12 & Memenuhi Syarat \\
\hline 2 & FLA & Terjadi Endapan Coklat $(+)$ & 655,535 & Memenuhi Syarat \\
\hline 3 & IDR & Terjadi Endapan Coklat $(+)$ & 1711,52 & Tidak Memenuhi Syarat \\
\hline 4 & FVT & Terjadi Endapan Coklat $(+)$ & 40,578 & Memenuhi Syarat \\
\hline 5 & BLB & Terjadi Endapan Coklat $(+)$ & 883,298 & Memenuhi Syarat \\
\hline
\end{tabular}

Open Journal System (OJS): journal.thamrin.ac.id

http://journal.thamrin.ac.id/index.php/anakes/issue/view/34 
Tabel 4.

Hasil Pemeriksaan Asam Benzoat Secara Kualitatif Dan

Kuantitatif Pada Margarin Bermerk Dalam Curah Yang Dijual Di Pasar Cisalak Depok

\begin{tabular}{|c|c|c|c|c|}
\hline \multirow{2}{*}{ NO } & $\begin{array}{c}\text { Sampel } \\
\text { Margarin } \\
\text { Bermerk } \\
\text { dalam } \\
\text { curah }\end{array}$ & Kualitatif & Kuantitatif & \multirow{2}{*}{$\begin{array}{c}\text { Memenuhi Syarat/ } \\
\text { Tidak Memenuhi syarat }\end{array}$} \\
\cline { 3 - 4 } & MGR 1 & Terjadi Endapan Coklat (+) & 2764,638 & Tidak Memenuhi Syarat \\
\hline 2 & MGR 2 & Terjadi Endapan Coklat (+) & 779,311 & Memenuhi Syarat \\
\hline 3 & MGR 3 & Terjadi Endapan Coklat (+) & 373,595 & Memenuhi Syarat \\
\hline 4 & MGR 4 & Terjadi Endapan Coklat (+) & 94,656 & Memenuhi Syarat \\
\hline 5 & MGR 5 & Terjadi Endapan Coklat (+) & 23,715 & Memenuhi Syarat \\
\hline
\end{tabular}

Dari hasil pemeriksaan terhadap 10 sampel margarin yaitu 5 sampel margarin bermerk dalam kemasan dan 5 sampel margarin bermerk dalam curah ternyata hasil pengujian laboratorium menunjukan bahwa ada sampel yang mengandung asam benzoat.

Dari 5 sampel margarin yang bermerk dalam kemasan didapat 1 sampel dengan kadar asam benzoat melebihi batas standar BPOM No. 36 Tahun 2013 yaitu pada sampel merk IDR dengan kadar asam benzoat $11711,52 \mathrm{mg} / \mathrm{kg}$. Dari 5 sampel margarin bermerk dalam curah didapat 1 sampel dengan kadar asam benzoat melebihi batas standar BPOM No. 36 Tahun 2013 yaitu pada sampel merk MGR 1 dengan kadar asam benzoat $2764,638 \mathrm{mg} / \mathrm{kg}$.

Kadar rata-rata margarin bermerk dalam kemasan dan margarin bermerk dalam curah yang dijual di Wilayah Pasar Cisalak Depok yaitu :

a. $\quad$ Margarin bermerk kemasan $=\frac{3.391,046}{5}=678,2092 \mathrm{mg} / \mathrm{kg}$

b. Margarin bermerk curah $=\frac{4.035,92}{5}=807,184 \mathrm{mg} / \mathrm{kg}$

Perbandingan kadar rata-rata asam benzoat pada margarin yang dijual Di Wilayah Pasar Cisalak Depok dilanjutkan dengan melakukan Uji Paired Samples Test sebagai berikut :

Tabel 5.

\section{Hasil Uji T Margarin Bermerk Dalam Kemasan Dengan Margarin Bermerk Dalam Curah Di Wilayah Pasar Cisalak Depok}

\begin{tabular}{|c|c|c|c|}
\hline Margarin & $\mathrm{t}$ & $\mathrm{df}$ & P.Value \\
\hline Kemasan dan Curah &,- 187 & 4 & 0,861 \\
\hline
\end{tabular}

Open Journal System (OJS): journal.thamrin.ac.id 
Berdasarkan uji $\mathrm{T}$ diperoleh $\mathrm{t}$ hitung sebesar 0,187 dan nilai $\mathrm{t}$ tabel 2,306 ( $\mathrm{t}$ hitung $<\mathrm{t}$ tabel ), dan nilai signifikasi sebesar 0,861 >0,05. Maka $\mathrm{H}_{\mathrm{o}}$ diterima yang berarti bahwa kadar Asam benzoat pada sampel Margarin bermerk dalam kemasan dan bermerk dalam curah yaitu tidak sama atau tidak ada berbeda.

\section{Pembahasan}

Dari hasil penelitian 10 sampel margarin didapatkan sampel positif $(+)$ pada uji $\mathrm{FeCl}_{3}$ dan secara spektrofotometri didapatkan kadar yang tertinggi 2.764,638 mg/kg. Hal ini menunjukkan masih ada produsen margarin yang menambahkan asam benzoat ke dalam produknya melebihi batas standar dari BPOM yaitu $1000 \mathrm{mg} / \mathrm{kg}$. Asam benzoat dalam bentuk garamnya digunakan untuk pengawet, meskipun diperbolehkan akan tetapi harus sesuai dengan batas standar BPOM. Penggunaan asam benzoat yang berlebihan akan menyebabkan gangguan kesehatan seperti muntah-muntah, diare, atau pusing. Margarin yang mengandung asam benzoat jika dikonsumsi dalam jangka panjang akan mengakibatkan penyakit kanker.

Dari hasil uji $\mathrm{T}$ antara kadar asam benzoat pada margarin bermerk dalam kemasan dan margarin bermerk dalam curah tidak ada perbedaan margarin bermerk dalam kemasan dan margarin bermerk dalam curah pada saat proses penambahan asam benzoat menggunakan takaran yang sama banyaknya hanya dibedakan pengemasannya saja untuk margarin bermerk dalam kemasan menggunakan kemasan atau packing dengan dituliskan nama merk dan komposisi sedangkan margarin bermerk dalam curah dikemas dengan plastik yang dilapisi dengan kardus.

Asam benzoat dalam bentuk garamnya digunakan untuk pengawet dan ada yang memenuhi syarat dan tidak memenuhi syarat maksimal $1000 \mathrm{mg} / \mathrm{kg}$. Adapun penambahan bahan pengawet asam benzoat untuk memperpanjang waktu penyimpanan agar sesuai dengan batas waktu penyimpanan dan agar dapat dikonsumsi secara aman oleh konsumen. Jika melebihi batas maksimal menyebabkan toksisitas dalam jangka waktu yang panjang.

\section{SIMPULAN}

Dari hasil penelitian dapat diambil kesimpulan : Dari 10 sampel margarin yang bermerk dalam kemasan dan bermerk dalam curah didapat hasil, semua ternyata mengandung Asam Benzoat dengan kadar rata-rata pada margarin bermerk dalam kemasan 678,2092 mg/kg dan kadar rata-rata pada margarin bermerk dalam curah $807,184 \mathrm{mg} / \mathrm{kg}$. Terdapat sampel mararin yang melebihi batas standar BPOM yaitu pada margarin bermerk dalam kemasan merk IDR dengan kadar 1711,52 mg/kg dan margarin bermerk dalam curah merk MGR 1 dengan kadar 2764,638 mg/kg. Dari hasil uji T tidak ada 
perbedaan yang nyata antara kadar asam benzoat pada margarin bermerk dalam kemasan dan margarin bermerk dalam curah

\section{UCAPAN TERIMA KASIH}

Penulis mengucapkan terima kasih kepada Kepala Laboratorium Kimia Fakultas Kesehatan Universitas MH Thamrin Jakarta dan Prodi D III Analis Kesehatan Fakultas Kesehatan Universitas MH Thamrin. dalam penelitian ini.

\section{DAFTAR PUSTAKA}

1. Awang, 2003. Medan : Gambaran Kandungan Natrium Benzoat.

2. Badan POM, 2013 Republik Indonesia Batas Maksimum Penggunaan Bahann Tambahan Pangan Pengawet, Jakarta.

3. Cahyadi, Wisnu, 2008, Analisis \& Aspek Kesehatan Bahan Tambahan Pangan, Edisi II, Cetakan pertama Bumi Aksars, Jakarta.

4. Cahyadi, Wisnu, 2012, Analisis \& Aspek Kesehatan Bahan Tambahan Pangan, Edisi II, Cetakan pertama Bumi Aksars, Jakarta.

5. Departemen Pertanian RI, 2002 Penggunaan Bahan Tambahan Kimia pada Industri Pengolahan Buah/Sayuran, Jakarta.

6. Direktorat Jenderal Pengawasan Obat \& Makanan, Farmakope Republik Indonesia, 1995, Departemmen Kesehatan, edisi cetakan ke empat, Jakarta.

7. Ketaren, S, 1995 Minyak \& lemak pangan, Universitas Indonesia (UI-Press), Jakarta.

8. Kusnandar, ferri, 2011, Kimia pangan komponen makro, PT.Dian Rakyat, Jakart.

9. Peraturan Kepala Badan Pengawasan Obat dan Makanan Nomor 036 tahun 2013, Batas Maksimum penggunaan Bahan Tambahan Pangan Pengawet.

10. Peraturan Menteri Kesehatan Republik Indonesia Nomor 33 tahun 2012, Bahan Tambahan Pangan.

11. Rohman, Abdul, Sumantri, 2007, Analisis makanan, Gajah Mada University Press, Yogyakarta.

12. Sawitri, Asti. 2010.konsentrasi dan ketebalan terhadap penyerapan cahaya (HUKUM BEER$L A M B E R T)$.FALKULTAS SAINS DAN TEKNOLOGI BANDUNG.

13. Standar Nasional Indonesia 3541. Tentang Margarin tahun 2014.

14. Tambunan, E, Ronal, 1991, Penelitian Bahan Pengawet Dalam Minuman Sirup Secara Spektrofotometer, Laporan Penelitian, UI.

15. Winarno, F. G., 2004, Kimia Pangan dan Gizi, PT. Gramedia Pustaka Utama, Jakarta

16. Yayasan Lembaga Konsumen Indonesia, 2003. Bahan Tambahan Makanan.

17. Yuliarti, Nurheti, 2007, Awas! Bahaya Di Balik Lezatnya Makanan, Yogyakarta 